\title{
LAS REGLAS CONSTITUCIONALES PARA LA APLICACION DE LA NORMA LABORAL
}

\author{
Javier Neves Mujica
}

\section{A. INTRODUCCION}

Las normas son fórmulas genéricas y abstractas diseñadas para la regulación de los hechos específicos y concretos que resulten comprendidos en sus supuestos. El proceso de adaptación del precepto general al caso particular, exige a la instancia declaratoria del derecho la consideración de ciertos criterios que rigen la aplicación de la normativa. Estos criterios están, en sus lineamientos básicos, contenidos en la Constitución, la que es complementada al respecto por determinadas normas importantes. Siendo así, las reglas para la aplicación del ordenamiento son, en un inicio, comunes a todas las áreas jurídicas, integrando una materia conocida como teoría general del derecho. Sin embargo, las peculiaridades de cada área jurídica conllevan generalmente la imposición de modificaciones sustanciales a esas reglas comunes. Este es, sin duda, el caso del Derecho del Trabajo que, sustentándose en la teoría general del sistema jurídico, tiene una lectura singular de algunas de sus principales instituciones.

El propósito de este trabajo es realizar una sistematización de los más importantes criterios que deben orientar la aplicación de la normativa laboral en cada uno de los supuestos esenciales en que esa tarea pudiera resultar compleja, que son los identificados en el sumario precedente. Este esfuerzo, que se emprende con la finalidad de brindar un instrumento útil a los operadores del derecho, señalará en cada caso los problemas especiales que se presenten y, si las hubiera, las diversas posiciones planteadas en los temas más polémicos. 
Queremos, finalmente, dejar expresa constancia de que muchas de las ideas aquí expuestas, han sido construidas colectivamente por el equipo docente del curso de Derecho Laboral, que dictamos en la Facultad de Derecho de la Universidad Católica. Como ha escrito Ribeyro, los conceptos pertenecen al dominio público, sólo las formas son privadas. Sin embargo, no pretendemos comprometer a sus integrantes con muchas de las afirmaciones efectuadas aqui, sobre todo respecto de los temas más controvertidos.

\section{B. IIGENCLA DE LAS NORMAS EN EL ESPACIO Y EN EL TIEMPO}

\section{En el espacio}

1. Estaremos ante un caso de Derecho del Trabajo Internacional -materia de conexión entre el Derecho Internacional Privado y el Derecho del Trabajo--, cuando una relación de trabajo tuviere elementos internacionales o extranacionales (Ermida Uriarte). Ubicándonos en nuestro país, el fenómeno descrito ocurriría si un contrato de trabajo se celebrara y ejecutara total o parcialmente dentro y fuera del Perú. La situación se presentará con frecuencia en las empresas o grupos de empresas transnacionales, en las que hubiere desplazamiento de trabajadores de un Estado a otro.

2. E1 primer asunto que debemos considerar es el concepto del territorio, ya que éste será la clave para determinar tanto la competencia jurisdiccional como la legislación aplicable. Según los artículos 97-99 Const., aquel comprende el suelo, subsuelo, dominio marítimo y espacio aéreo, éstos últimos hasta 200 millas marinas desde las costas. Este territorio, por un lado, en virtud de tratados internacionales, incluye a las sedes diplomáticas peruanas en países extranjeros, así como las naves de bandera peruana que naveguen en zonas marítimas o aéreas internacionales, y por el otro lado, excluye a las sedes diplomáticas de países extranjeros y de organismos internacionales en nuestro país. El espacio ocupado en el Perú por empresas extranjeras es territorio peruano, estando estas expresamente sometidas a las leyes y tribunales de 
nuestro país (art. 136 Const.). Nacionales y extranjeros residentes están sujetos al ordenamiento peruano; éstos últimos tienen limitaciones en número y remuneraciones en el desempeño de una actividad laboral (art. 42 Const. y D.L. 22452).

3. Constatada la existencia de una cuestión de Derecho del Trabajo Internacional, deberá seguirse una serie de pasos sucesivos para resolverla: los más importantes de ellos serán la determinación del juez competente y de la ley aplicable. Ambos factores deberán precisarse atendiendo a lo dispuesto por los tratados internacionales y, a falta de ellos, por nuestro ordenamiento (Mac Lean Ugarteche, citado por los hermanos Tovar Gil). En los puntos siguientes nos referiremos a este último.

4. Respecto de la competencia jurisdiccional, cabe señalar dos temas. En primer lugar, nuestro Poder Judicial tendrá en estricto sentido jurisdicción más que competencia sólo sobre asuntos sucedidos en nuestro territorio (art. 237 inc. 1 Const.). En segundo lugar, nuestro Derecho del Trabajo carece de reglas propias sobre esta materia, razón por la cual se aplican supletoriamente las contempladas en el Código Civil (art. IX T.P.). En virtud de éstas, los tribunales peruanos serán competentes: a) si el empleador demandado domiciliare en el territorio nacional (art. 2757), $y, b)$ por excepción, aun cuando domiciliara en país extranjero, si b.1) la relación laboral debiera ejecutarse o el contrato de trabajo se hubiera celebrado en el territorio nacional, o b.2) las partes se sometieran expresa o tácitamente, a la jurisdicción peruana (art. 2858 incs. 2 y 3). El criterio decisorio general es el domicilio.

5. Respecto de la ley aplicable, nuestro Derecho del Trabajo sí tiene criterios específicos y están previstos en los arts. 46 y 47 del reglamento de la Ley 4916. De conformidad con éstos, la ley peruana rige las relaciones laborales: a) que hubieran sido ejecutadas en el Perú, independientemente de si sus contratos de origen se hubieran celebrado en el Perú o en país extranjero (ley del lugar de cumplimiento), y, b) por excepción, que hubieran sido contratadas en el Perú, aunque se hubieran ejecutado en pais extranjero (ley del lugar de celebración). El criterio decisorio general es el lugar del cumplimiento. 
6. Cabe en este último tema, formularnos dos interrogantes muy vinculadas entre sí: ¿podría utilizarse supletoriamente el art. 2095 Cod. Civ.?, ¿habría lugar para acudir al principio de la norma más favorable? Según el artículo mencionado, las obligaciones contractuales se rigen en forma alternativa y sucesiva: a) por la ley expresamente elegida por las partes, b) en su ausencia, por la ley del lugar de cumplimiento, y c) si éste no pudiera determinarse, por la ley de lugar de celebración. Seguimos preguntando: en una relación laboral celebrada y/o ejecutada en el Perú, aunque con elementos internacionales o extranacionales, ¿podrían las partes elegir la ley aplicable?; en todo caso, ¿podríar hacerlo siempre o sólo si ésta fuera más favorable para el trabajador que la ley peruana?; por último, ¿podría el juez aplicar el principio de la norma más favorable, practicando la selección entre las legislaciones de los Estados involucrados?. Sin desconocer que esta difícil cuestión podría admitir más de una solución, nos inclinamos por una respuesta negativa, fundada en la naturaleza imperativa de las normas laborales nacionales en juego, que no deja margen para la autonomía de la voluntad ni para la norma más favorable. Creemos que el único resquicio para la libertad de elección de las partes serían las normas mínimas hacia arriba y no hacia abajo y las dispositivas, pero esta salida no derivaría de una interpretación del art. 2095 Cód. Civ., que permitiría el apartamiento tanto de normas imperativas como dispositivas (hermanos Tovar Gil), sino del carácter protector del Derecho de Trabajo. De otro lado, estimamos que sí procedería la aplicación supletoria del referido artículo del Código Civil para esclarecer el lugar de cumplimiento o determinar en su ausencia la aplicación de la ley del lugar de celebración.

7. Como puede apreciarse de lo expuesto hasta aquí, siempre que el juez peruano fuera competente, la ley aplicable sería la de nuestro país, salvo en el extraño supuesto en que, pese a no haberse ejecutado la relación laboral ni haberse celebrado el contrato respectivo en este territorio, el empleador demandado domiciliara en el Perú o las partes decidieran expresa o tácitamente someterse a la jurisdicción peruana, hipótesis en las cuales resultará aplicable la ley de un pafs extranjero. En ese caso, el juez peruano debería aplicar la ley del país correspondiente, excepto si ella contrariara 
el orden público internacional (art. 2049 Cod. Civ.) (hermanos Tovar Gil). En este raro supuesto que nos ocupa, para determinar la ley aplicable, debería utilizarse supletoriamente el art. 2095 Cód. Civ.

\section{En el tiempo}

8. El criterio general en esta materia es lá irretroactividad de las normas (art. 187 Const.). Las normas rigen normalmente desde su promulgación y publicación hacia adelante y no hacia atrás: a) la ley y el decreto legislativo, desde el décimo sexto día ulterior a su publicación, salvo disposición contraria (arts. 195 y 188 Const. y 3 inc. 1 Dec. Leg. 217); y b) el reglamento, desde el día que él mismo indique o, de no hacerlo, desde el día siguiente a su publicación (art. 3 inc. 2 Dec. Leg. 217). En el caso del convenio colectivo, como veremos después, la aplicación retroactiva ha sido generalizada.

9. La teoría imperante en nuestro sistema jurídico en cuestión de vigencia de las normas en el tiempo, es la de los hechos cumplidos, no por disposición constitucional que no opta a este respecto sino del Código Civil (art. III T.P.): la nueva norma tiene aplicación inmediata, regulando a los nuevos hechos y sus efectos, pero también a los efectos no cumplidos de los hechos anteriores (Rubio Correa). ¿Es conciliable la adopción de esta teoría con el respeto a los derechos adquiridos, tradicional en nuestro Derecho del Trabajo? Este asunto lo abordaremos al tratar el principio de la condición más beneficiosa.

10. La retroactividad de las normas consistiría en la aplicación de la nueva norma a hechos anteriores y a los efectos ya cumplidos de los mismos (Rubio Correa). Aquella es admitida en nuestro ordenamiento en materia laboral (y penal y tributaria), si la nueva norma es más favorable al trabajador (art. 187 Const.).

11. Creemos que la retroactividad, por ser una excepción a la regla, debería ser declarada en forma expresa. Esta declaración podría ser hecha a través de: a) una norma estructural, en virtud de la cual todas las normas de un determinado tipo que se produ- 
jeran serían automáticamente retroactivas; o b) una norma sustantiva, que para sí misma dispusiera su retroactividad. La prinicra modalidad está prevista en nuestro ordenamiento laboral para los convenios colectivos ( $\mathrm{y}$ en otras áreas jurídicas: en el Derecho Penal y en el Derecho Tributario es lo referido a las sanciones), y la segunda la utilizan las normas estatales. En el caso de los convenios colectivos, ellos normalmente rigen no desde la fecha de la celebración del acuerdo entre las partes o de la decisión sustitutoria emanada de un tercero dirimente, sino desde la presentación del respectivo pliego de reclamos (art. 47 D.S. 6-71-TR), comprendiendo a los trabajadores cesados durante el trámite de la negociación colectiva (Directiva jurisdiccional 18-SP-FTCCLL).

\section{DEFECTO O DEFICIENCIA NORMATIVA}

Antes de abordar cada una de estas situaciones, conviene recordar la precisa distinción entre ellas elaborada por Rubio Correa a partir de una interpretación sistemática de la Constitución. el Código Civil y la Ley Orgánica del Poder Judicial. Según ese autor, el defecto consiste en la insuficiencia de la norma y se resuelve con su interpretación, y la deficiencia consiste en la inexistencia de la norma y se resuelve con su integración.

\section{Defecto}

12. Por ser toda norma una regla general que requiere ser adaptada por el juez al caso particular, como ya hemos dicho, hará falta siempre a estos efectos establecer su interpretación. En verdad, no es esta interpretación simple la que proviene propiamente de un defecto de la norma, sino que éste provocará la necesidad de una interpretación compleja: ante la oscuridad de la norma, deberá aclararse su sentido. Estaremos, en rigor, ante un caso de duda. ¿Cómo escoger uno entre los dos o más sentidos que la norma tiene?

13. E1 Derecho Civil ha formulado diversos métodos, derivados de concepciones distintas, para solucionar el supuesto descrito: literal. lógico, sistemático, histórico, sociológico, etc. (Rubio Correa). En nuestro ordenamiento, esta tarea plantea tres proble- 
mas fundamentales: el primero consiste en que ninguna norma señala los métodos de interpretación de las normas, como sí lo hace el Código Civil (art. 168-170) respecto de los criterios de interpretación de los actos jurídicos; el segundo, consiste en que no existe, en consecuencia, un orden de aplicación de los variados métodos; y el tercero, consiste en determinar la relación entre los criterios mencionados y el principio del in dubio pro operario, específico del Derecho del Trabajo para esa hipótesis. Los dos primeros problemas pueden ser enfrentados eficazmente, recogiendo los diversos métodos aceptados por el derecho comparado más próximo y aplicándolos combinadamente. Una buena fuente de inspiración al respecto podría ser el art. 3 del Código Civil español: "Las normas se interpretarán según el sentido propio de sus palabras, en relación con el contexto, los antecedentes históricos y legislativos, y la realidad social del tiempo en que han de ser aplicadas, atendiendo fundamentalmente al espíritu y finalidad de aquéllas". El tercer problema vamos a tratarlo a continuación.

14. Los jueces no pueden dejar de administrar justicia por defecto de la ley, debiendo aplicar en tal caso los principios generales del derecho (art. 233 inc. 6 Const. y art. VIII T.P. Cód. Civ.). En caso de duda sobre el alcance y contenido-de cualquier disposición laboral, se optará por la interpretación más favorable al trabajador (art. 57 Const.). ¿Cómo ensamblar el principio del in dubio pro operario con los métodos clásicos de interpretación de las normas? ¿Es posible establecer de antemano una preferencia? Creemos que es muy difícil en este punto establecer un criterio apriorístico con validez general, sin apreciar todas las circunstancias de cada caso que el juez deberá tener en cuenta. Sin embargo, pensamos que resultará siempre natural aplicar primero el método literal, dado que no cabe forzar la interpretación, y, si subsistiera la duda, acudir antes al principio específico de nuestra disciplina que a las reglas comunes a todo el ordenamiento. No podemos olvidar que el in dubio pro operario justifica su existencia en la desigualdad real de los sujetos de la relación laboral, al igual que los demás principios del Derecho del Trabajo, debiendo ser por ello preferido frente a los criterios clásicos que presuponen una igualdad entre las partes. De la Cueva señalaba que nuestra 
área jurídica debería optar por una interpretación finalista y no formalista de las normas, y el propósito de esta disciplina es la protección al trabajador.

15. El principio del in dubio pro operario está recogido en nuestra Constitución, en los términos siguientes: "En la interpretación o duda sobre el alcance y contenido de cualquier disposición en materia de trabajo, se está a lo que es más favorable al trabajador" (art. 57). La fórmula asumída exige plantear aunque sea brevemente cinco temas. En primer lugar, pareciera que en toda interpretación y no sólo la que ofreciera dudas, cabría la aplicación del principio, cuestión que ya hemos expuesto y desechado. En segundo lugar, la duda podría recaer sobre el ámbito subjetivo (alcance) u objetivo (contenido) de la norma: a quiénes comprende y qué manda. En tercer lugar vamos a ver en el punto siguiente, de qué tipos de disposiciones estamos hablando. En cuarto lugar, por materia de trabajo debemos entender todo aquello que tuviera a los trabajadores como destinatarios. Y, en quinto lugar, como han señalado algunos autores, si hubiera duda respecto de lo que fuera más favorable para el trabajador, el juez debería permitirle a éste practicar la elección.

16. La disposición dudosa podrá ser: a) una norma heterónoma (cualquier norma estatal); o b) una norma autonóma (convenio colectivo o reglamento interno de trabajo). Respecto del convenio colectivo podríamos preguntarnos si el principio se aplicará también a su parte obligacional o sólo a la normativa. Si bien en la parte obligacional existe en rigor un contrato paritario, por lo que podría no haber fundamento para favorecer al sindicato, creemos que es más conveniente optar por un criterio unitario para la interpretación de todo el convenio colectivo. ¿Se extenderá el principio a la interpretación del contrato de trabajo y/o de los hechos? En el caso del contrato de trabajo, pensamos que no pueden resultar de aplicación las reglas previstas en el Código Civil para la interpretación de los actos jurídicos, aunque aquél sea uno de éstos, porque -ya lo hemos dicho- presuponen la paridad, que aquí no se da. El propio Código Civil exceptúa de esas reglas a los contratos no paritarios producidos en su ámbito, como es el caso de los celebrados a partir de cláusulas generales de contratación, cuya in terpreta- 
ción en caso de duda debe hacerse en favor del contratante (art. 1401 ). En el caso de los hechos que debieran ser acreditados en un proceso, el asunto es bastante controvertido. La discrepancia no comprende la prueba de la existencia de la costumbre, que debe ser realizada por quien la alega, sino a los demás hechos referidos por las partes. En realidad, en esta materia debemos atenernos a las reglas procesales sobre la carga de la prueba, que podrían favorecer al trabajador si las normas lo previeran expresamente mediante el juego de los apercibimientos, presunciones, etc. En nuestro ordenamiento, el trabajador debe probar la existencia de la relación laboral y el empleador su cumplimiento de las disposiciones legales o convencionales (art. 32 D.S. 3-80-TR y art. 34 D.S. 6-72-TR), sin tener el primero ningún favorecimiento para ese fin (no existe entre nosotros, por ejemplo, la presunción de que toda prestación de servicios es en principio laboral, salvo prueba en contrario). En lo referido a la valoración de la prueba creemos que no cabe la aplicación del principio o debería utilizarse en todo caso como último recurso.

\section{Deficiencia}

17. Nos encontramos ante una deficiencia cuando un hecho no está regulado por ninguna norma. Para esa situación. denominada laguna, nuestro ordenamiento ha previsto la siguiente secuencia: a) constatada la presencia de una laguna en un caso concreto, cl juez no puede dejar de resolverlo, sino que debe brindarle una respuesta específica a través de alguno de los métodos de in tegración (art. 233 inc. 6 Const. y art. VIII T.P. Cód. Civ.); b) luego, debe dar cuenta de esa situación a sus superiores, para que éstos a su vez hagan lo propio con el Congreso (art. X T.P. Cód. Civ. y art. 115 inc. 5 LOPJ); c) la Corte Suprema tiene derecho de iniciativa legislativa en este campo, por lo que puede presentar al Congreso el proyecto de ley correspondiente (art. 190 Const. y arts. 115 inc. 5 y 137 inc. 3 LOPJ); y d) por último, el Congreso, tomando en cuenta el proyecto de ley elaborado por el Poder Judicial u otro, debe subsanar la inexistencia normativa, creando la norma respectiva. Esta misma secuencia, con pocas y evidentes variaciones, se daría en el supuesto del defecto normativo, antes tratado. La deficiencia -como el defecto- debería, pues, ser una situación transi- 
toria. De otro lado, en lo que toca a la deficiencia de las leyes, las autoridades administrativas tienen igual responsabilidad que las judiciales - de no dejar de resolver el caso concreto-, debiendo acudir a las fuentes supletorias del Derecho Administrativo (art. 2 del Reglamento de Normas Generales de Procedimientos Administrativos).

18. Tanto en el caso de la integración como de la interpretación, no encaja con el esquema descrito en el punto anterior que el Poder Judicial produzca directamente normas, es decir, realice cualquiera de las dos tareas mencionadas con efectos generales y no particulares (en el caso de interpretación, es más obvio aún: según el art. 186 inc. 1 Const., sólo el Congreso interpreta las leyes). Esto pone sobre el tapete el espinoso tema de las directivas mal llamadas jurisdiccionales, que son verdaderas normas (art. 8 Dec. Leg. 384). Creemos al respecto, como solución provisional a la pendiente integración plena del Fuero de Trabajo al Poder Judicial (que mediante una eventual casación ante la Corte Suprema pudiera homogenizar las sentencias dispares de los diversos tribunales de trabajo), que las directivas son medidas aceptables y convenientes.

19. Los dos principales métodos de integración, comúnmente admitidos, son la analogía y los principios generales del derecho. La primera consiste en aplicar la norma que regula un hecho a otro que carece de ella, pero que guarda con el primero una semajanza sustancial (Rubio Correa). Los segundos son las ideas fundamentales que informan una normativa, bien sea obtenida por abstracción de las normas singulares que la componen o, agotadas éstas, del derecho natural o científico (Albaladejo, citado por Rubio Correa).

20. Este tema plantea algunos problemas en nuestro ordenamiento, por cuanto la analogía no aparece expresamente reconocida como un método de integración, al lado de los principios generales que sí están mencionados. ¿Cabe acudir a la a nalogía para resolver una laguna? Las únicas referencias a ella en nuestro sistema jurídico son para excluirla: en materia penal (art. 233 inc. 8 Const.) (Muñoz Conde considera que la analogía favorable al reo debería ser aceptada) y cuando se establezca excepciones o restrinja dere- 
chos (art. IV T.P. Cód. Civ.). Frente a ello caben dos posibilidades: la consideramos eliminada o la admitimos pese a su falta de recepción expresa. Nos inclinamos por esta segunda opción, ya sea por estimarla comprendida dentro del concepto de los principios generales, operación que practican algunos autores (Rubio Correa), como por entender que, al igual que éstos, la analogía no requiere de mención expresa para ser aceptada, limitándose ésta sólo a reforzarla (Plá Rodríguez).

21. ¿Hay algún orden en la aplicación de los métodos de integración? Consideramos que debería utilizarse primero la analogía que los principios generales, por cuanto aquella nos permite permanecer dentro del ordenamiento positivo, sin salir de él a buscar la solución, tarea a la que nos fuerzan los últimos. Más complejo podría ser determinar una prioridad entre la analogía y la supletoriedad. En ésta, si una norma no contiene regulación para un hecho, se aplica otra que sí la contiene, porque entre ambas hay una remisión. En nuestro sistema juridico, el Derecho Civil es supletorio del Derecho del Trabajo, siempre que no haya incompatibilidad de naturaleza (art. IX T.P. Cód. Civ.). Si no existiera una norma laboral que rigiera un hecho, ¿deberíamos acudir primero al campo civil. definid o como supletorio, a indagar por una respuesta?, ¿o deberíamos quedarnos en el campo laboral e intentar encontrarla antes aquí, mediante la analogía o los principios generales? Pensamos que lo más técnico sería utilizar primero la supletoriedad del Derecho Civil, dado que por esta vía tendremos una norma aplicable vinculada con la laboral por envío previo y expreso, y después, acudir a la analogía o, por último, a los principios generales, que nos proporcionarán una norma o un criterio aplicable, respectivamente, encontrados en forma posterior a la constatación del problema. Este dilema no se presentará en el terreno procesal, en el cual a falta de regulación laboral se aplicará la civil (art. 68 D.S. 3-80-TR, art. 62 D.S. 6-72-TR y art. 55 D.S. 6-71-TR), sino en el sustantivo y de modo sumamente excepcional, por cuanto la supletoriedad civil brindará una respuesta a las cuestiones más generales, que podría además ser incompatible con la naturaleza del Derecho del Trabajo, y la analogía laboral solucionará los asuntos más específicos. Ejemplificando, diremos que el Derecho Civil nos servirá para determinar ciertos conceptos básicos sobre los derechos de 
personas, familia, actos jurídicos, obligaciones, contratos, etc., que podrían ser utilizables en el ámbito laboral, pero no nos permitirá extender a los empleados un beneficio creado para los obreros, que no fuera inherente al diverso tipo de labor ejecutada por ambas categorías, misión que el procedimiento analógico realiza con frecuencia.

\section{CONFLICTO O SUCESION NORMATIVA}

\section{Conflicto}

22. El conflicto supone la regulación simultánea de un mismo hecho por dos o más normas vigentes, de contenidos incompatibles entre sí. En esa hipótesis se hace necesario escoger una sola de las normas en cuestión, desplazando a la otra u otras del caso concreto, pero sin eliminarlas del ordenamiento (Martín Valverde). La norma seleccionada, bajo ciertas condiciones, será la más favorable al trabajador (Camps Ruíz).

23. El principio específico del Derecho del Trabajo para el supuesto de conflicto es, pues, el de la norma más favorable. Esta afirmación requiere, sin embargo, un análisis más profundo, por cuanto surgen inmediatamente tres interrogantes: ¿todo tipo de conflicto conduce al desplazamien to de una de las normas en juego, o algunos llevan a la eliminación de una de ellas? ¿el principio aludido se aplica sólo en la hipótesis de conflicto o se extiende a otras de concurrencia no conflictiva? ¿cómo se relaciona el principio de la norma más favorable, específico del Derecho del Trabajo, con las reglas clásicas de jerarquía, especialidad y temporalidad que rigen las situaciones de conflictos en el derecho común? Respecto del primer problema, Martín Valverde distingue en tre la contradicción y la divergencia, a partir de la comprobación de la existencia o no de una negación recíproca entre los preceptos antinómicos, que ocurre en la primera pero no en la segunda, reservando el concepto de conflicto en sentido estricto para la divergencia. En ésta el órgano productor y el ámbito de regulación de ambas normas son parcialmente coincidentes, pero no idénticos. Mientras en la divergencia, entonces, habría inaplicación de uno de los preceptos al caso particular, en la contradicción la colisión se resolvería 
con la eliminación de uno de los preceptos. En definitiva, el primero sería propiamente un tema de conflicto, en tanto que el segundo lo será más bien de la sucesión, cuestión que trataremos en el tema siguiente.

24. El segundo problema, referido a la extensión o no del principio de la norma más favorable más allá de los límites del conflicto, genera discrepancias en la doctrina: Camps Ruiz lo considera aplicable también al supuesto de suplementariedad, en el cual una norma mínima es mejorada por otra, que por ser la más ventajosa para el trabajador será la que regule el caso; en cambio, para Martín Valverde, en la suplementariedad se da la aplicación simultánea de ambas normas, dado que el mejoramiento por la segunda de ellas estaba previsto por la primera, siendo innecesario e improcedente acudir al criterio de la norma más favorable en este caso. Nosotros adherimos al planteamiento de este último autor, en tanto entendemos que en la suplementariedad la norma más ventajosa absorbe a la otra, sin suprimirla ni excluirse, por lo que su aplicación conlleva la de ambas a la vez.

25. El problema de la relación entre el principio de la norma más favorable y las reglas de jerarquía, especialidad y temporalidad, comunes al ordenamiento, vamos a analizarlo desagregadamente en cada uno de los supuestos de conflicto. Para estos efectos, debemos señalar antes - siguiendo a Camps Ruiz-que en este ámbito es necesario tener en cuenta tres tipos de límites que encauzan la utilización del principio: materiales, instrumentales y aplicativos. Los límites materiales se refieren a los contenidos respecto de los cuales actúa el principio: la divergencia debe producirse entre normas válidas en fondo y forma, ya que si una de ellas no lo fuera, por haber transgredido las reglas sobre jerarquía, competencia o procedimiento, el conflicto sería sólo aparente, puesto que aquella norma debería ser eliminada del ordenamiento (Camps Ruiz). Este sería el caso, por ejemplo, de un reglamento que concediera más ventajas al trabajador que las otorgadas en una ley, o de un convenio colectivo que vulnerara las pautas comúnmente mínimas o excepcionalmente máximas fijadas por una ley, o de una costumbre contraria a una ley. 
26. Los límites instrumentales aluden a las normas entre las que actúa el principio (Camps Ruiz). En nuestro ordenamiento hemos identificado cinco supuestos al respecto:

\section{a. Normas estatales}

Las normas estatales se rigen en sus conflictos por los criterios clásicos de jerarquía, especialidad y temporalidad, conduciendo aquellos frecuentemente a contradicciones y no a divergencias. $\mathrm{Si}$ se tratara de normas de diversa jerarquía, la superior prevalecerá sobre la inferior (art. 87 Const.), no habiendo espacio para lia aplicación del principio de la norma más favorable, y ni siquiera para la suplementariedad. Si las normas tuvieran el mismo nivel deberíamos distinguir: a) si fueran dos normas generales entre sí o dos especiales entre sí, la posterior prevalecerá sobre la anterior; o b) si fuera una especial y una general, la primera prevalecerá sobre la segunda, generándose cierta dificultad si, b. 1) una norma general posterior más favorable entrará en conflicto con otra especial, a la que no derogara expresamente, y b. 2) una norma especial posterior menos favorable entrara en conflicto con otra general. En estos dos últimos casos, con bastantes reservas, podría preferirse el principio específico de la norma más favorable sobre la regla genérica de la especialidad.

\section{b. Norma estatal y convencional}

Aunque las normas estatales suelen tener carácter mínimo para las convencionales, por lo que no es usual un conflicto entre ellas, si éste se produjera deberá resolverse mediante la aplicación del principio de la norma más favorable. Normalmente la norma seleccionada a través de este mecanismo será el convenio colectivo, salvo en el extraño supuesto de que la norma estatal se hubiera creado después, con un contenido mejor.

\section{c. Normas convencionales}

Dado que la negociación colectiva en nuestro país se produce generalmente a nivel de empresa o, por excepción, a nivel de rama de actividad, pero siempre en forma excluyente y no simultánea 
(las causas habría que encontrarlas en las resistencias de los empleadores y autoridades), no se producirán superposiciones entre los ámbitos de vigencia de dos convenios colectivos. En este supuesto inexistente, podría haber lugar para un conflicto (al lado de otras relaciones posibles, como la competencia, suplementariedad, complementariedad, etc.), que podría a su vez ser resuelto por el principio de la norma más favorable, que no constituye la única solución posible (cabría también utilizar de alguna manera las reglas clásicas), pero sí la más conveniente desde nuestro punto de vista.

\section{d. Norma internacional y estatal o convencional}

Pese a que las normas internacionales incorporadas a nuestro derecho interno tienen nivel constitucional si se refieren a derechos humanos (art. 105 Const.) o superior al legal si son comunes (art. 101 Const.), serán desplazadas por las normas estatales o convencionales, siempre que éstas establecieran mejores derechos. Así lo han previsto expresamente los principales instrumentos internacionales sobre derechos humanos: Pacto Internacional de Derechos Civiles y Políticos (art. 5 inc. 2), Pacto Internacional de Derechos Económicos, Sociales y Culturales (art. 5 inc. 2), Convención Americana sobre Derechos Humanos (art. 29) y Constitución de la Organización Internacional del Trabajo (art. 19 inc. 8). En consecuencia, en este campo se aplicará el principio de la norma más favorable.

\section{e. Normas internacionales}

También en este caso es el principio de la norma más favorable, la solución diseñada por los instrumentos internacionales sobre derechos humanos para resolver sus eventuales conflictos. Así está establecido en forma bastante general (comprendiendo en rigor otros supuestos) en el Pacto Internacional de Derechos Civiles y Políticos (art. 46), el Pacto Internacional de Derechos Económicos, Sociales y Culturales (art. 24) y la Convención Americana sobre Derechos Humanos (art. 29). Adicionalmente, los dos Pactos mencionados (en sus arts. 22 inc. 3 y 8 inc. 3 , respectivamente) adoptan el mismo criterio para enfrentar cualquier divergencia qui 
pudiera surgir entre aquellos y el Convenio 87 OIT en materia específica de la libertad sindical.

27. La cuestión de un posible conflicto entre una norma nacional y otra extranjera, y de una eventual aplicación del principio de la norma más favorable a ese supuesto, que forma parte del Derecho del Trabajo Internacional, ya la hemos abordado en el punto 6 de este trabajo, al cual nos remitimos.

28. Por último, los límites aplicativos aluden a la unidad de comparación que debe utilizarse entre las normas (Camps Ruiz). La cuestión no ofrece dificultad cuando se trata de un solo derecho y éste es traducible cuantitativamente, sólo que en tal caso estaremos seguramente ante un supuesto de suplementariedad y no de conflicto. El asunto se complica cuando: a) tenemos varios derechos contenidos en las normas, en alguno de los cuales una de éstas es más beneficiosa que la otra, siendo menos beneficiosa en otro de aquellos; o b) son derechos de tipo cualitativo. Para estas hipótesis, podrá optarse por la teoría del conjunto (que realiza la comparación en forma global entre las normas), la acumulación (que compara entre preceptos de una y otra norma) o la inescindibilidad (que hace la comparación entre unidades conceptuales al interior de cada norma) (Pla Rodríguez, Camps Ruiz, Martín Valverde). Los tres autores referidos acogen esta última teoría, que también nos parece la más apropiada. Si no hubiera certeza sobre la mayor favorabilidad de una u otra norma, el juez debería dejar la elección en manos del trabajador.

\section{Sucesión}

29. El supuesto de sucesión se verifica cuando una norma es eliminada del ordenamiento por otra, bien sea por derogación o anulación (Martín Valverde). La derogación se produce - según ese autor - cuando una norma posterior de suficiente nivel (igual o mayor) suprime a otra anterior. En nuestro ordenamiento, la derogación puede derivar de: a) declaración expresa; b) incompatibilidad (por contradicción y no por divergencia) entre la nueva norma y la anterior; o c) regulación íntegra de la materia de la primera norma por la segunda (art. I T.P. Cód. Civ.). La anulación pueden 
decretarla el Tribunal de Garantías Constitucionales y el Poder Judicial, respectivamente, cuando una norma de inferior nivel transgrede a otra superior: a) una ley que sea inconstitucional (art. 298 inc. 1 Const. y Ley 23385); o b) un reglamento que sea inconstitucional o ilegal (art. 295 Const. y Ley 24968).

30. En materia laboral, comúnmente la sucesión es mejorativa y no peyorativa en cuanto a los contenidos normativos, por la tendencia progresiva y no regresiva que caracteriza en circunstancias normales a esta área jurídica. En la hipótesis frecuente de la sucesión mejorativa, no habrá ninguna dificultad para la aplicación inmediata de la nueva norma, conforme con la teoria de los hechos cumplidos asumida por nuestro Código Civil (art. III T.P.).

31. El problema se presenta en el supuesto excepcional de una sucesión peyorativa. Aquí debemos practicar dos distinciones: ¿es indiferente la posición adoptada por la nueva norma sobre su afectación a las situaciones y relaciones existentes? ¿Es igual que las normas que se suceden sean estatales entre sí o convencionales entre sí? La primera interrogante debe ser respondida negativamente. La nueva norma puede tener respecto de los derechos nacidos de la anterior, una de las tres posiciones siguientes: a) se pronuncia expresamente por el respeto a los derechos adquiridos, b) guarda absoluto silencio, y c) declara expresamente su aplicación inmediata, comprendiendo a las situaciones existentes y a las futuras. El caso uno es el más frecuente en nuestro ordenamiento laboral, en el que las disposiciones transitorias de las nuevas normas suelen contener referencia expresa a su respecto a los derechos adquiridos. El caso tres, sumamente excepcional, nos pone en el dilema de escoger entre un principio no recogido por ninguna norma y una norma que lo niega, situación en la que no cabe sino optar por la segunda (Plá Rodríguez). Es el caso dos, en consecuencia, el único en el que podría plantearse la alternativa: ¿aplicación inmediata o derechos adquiridos? Vamos a detenernos en este tema en el punto siguiente. Respecto de la segunda interrogante arriba planteada, hay dos posiciones doctrinales: a) se trata igual la sucesión de normas estatales que la de las convencionales; o b) se adopta un criterio distinto para esta última, dado que su sucesión peyorativa toca al tema de la renuncia de derechos, que a su vez, 
b. 1) algunos autores admiten en ese caso, y b. 2) otros no (este tema lo abordaremos en el punto correspondiente de este trabajo). Nosotros nos inclinamos por brindar la misma respuesta en el sentido de garantizar el respeto por los derechos adquiridos en ambas hipótesis, reconociendo incluso un mayor sustento en la segunda que en la primera, por la conservación de la vigencia de los convenios colectivos hasta su sustitución por otros previsiblemente mejores (art. 44 D.S. 6-71-TR) y la contemplación expresa del principio de la irrenunciabilidad de derechos (art. 57 Const.), que resolvería en favor de los trabajadores el caso dos pero también el tres, por existir en éste una nulidad.

32. Ubicándonos en el supuesto de la sucesión normativa peyorativa, surgirá una nueva y fundamental discrepancia doctrinaria: ¿será o no de aplicación el principio de la condición más beneficiosa a ese supuesto? Este principio permite la conservación de las ventajas alcanzadas por el trabajador, a pesar de la eliminación y sustitución peyorativa del acto que las produjo, pero ¿sólo de las ventajas de origen contractual o también de los de origen normativo? Algunos autores consideran que el principio actúa: a) únicamente en el supuesto de condiciones de origen contractual frente a las establecidas en nuevas normas que sustituyan a las anteriormente vigentes (Sala Franco); mientras para otros, b) opera además en el supuesto de condiciones de origen normativo (Ojeda Avilés). Hay acuerdo, en consecuencia, en que las ventajas pactadas en un contrato de trabajo, concedidas por el empleador unilateralmente $o$ producidas de hecho y consolidadas por el transcurso del tiempo, deben ser respetadas por el empleador, pudiéndosele oponer el principio de la condición más beneficiosa a cualquier acto de aquel que pretendiera vulnerarlas. El desacuerdo aparece otra vez respecto de la modificación bilateral de esas ventajas, tema de nuevo propio de la renuncia de derechos que trataremos en ese punto.

33. El problema principal se encuentra, pues, en la aplicación del principio de la condición más beneficiosa a la sucesión normativa peyorativa. En nuestro ordenamiento, ya lo hemos dicho, rige la teoría de la aplicación inmedia ta de la nueva norma. ¿cómo sustentar, entonces, la subsistencia de los derechos ad- 
quiridos, nos preguntamos en el punto 9 de este trabajo? Los autores que lo hacen se apoyan en la incorporación al nexo contractual de los mandatos normativos, cuestión que ocurre cuando éstos han tenido aplicación efectiva a aquel (Ojeda Avilés). Nosotros consideramos que en el Derecho del Trabajo, por su peculiar carácter protector del trabajador, tanto la vigencia retroactiva - como ya vimos- como la aplicación inmediata, están condicionadas a su benignidad. Esto significa que en nuestra área jurídica impera también la teoría de los hechos cumplidos (y no la opuesta, de los derechos adquiridos, que supondría la regulación total del hecho, para lo favorable y lo desfavorable, por la norma a cuyo amparo se produjo), pero con un matiz fundamental: la nueva norma tendrá aplicación inmediata siempre que mantenga o mejore los derechos de los trabajadores; en caso contrario, cada uno de éstos le podría oponer el principio de la condición más beneficiosa para conservar su ventaja. Debemos recordar que el Derecho Civil es supletorio del Derecho del Trabajo, siempre que no haya incompatibilidad de naturaleza, como la que aquí se produciría si adoptáramos la teoría civil en su forma pura.

34. Finalmente, cabe señalar dos importantes características del principio de la condición más beneficiosa, que operan como límites del mismo: a) si la normativa anterior conced ía un derecho, a.1) en forma más beneficiosa que la nueva, inhibe la aplicación de ésta sin acumularse ambas ventajas, pero a.2) si la normativa sustituyente no contempla un derecho concedido por la anterior, si habría acumulación (Ojeda Avilés); y b) si la nueva norma establece un derecho mejor (en materia salarial o, al menos, traducible numéricamente), las ventajas anteriores se extinguen; compensándose con las nuevas mayores, siempre que haya mandato expreso al respecto (Sala Franco).

\section{E. RENUNCIA DE DERECHOS POR EL TRABAJADOR}

35. La rẹuncia ha sido definida por De la Villa, como un negocio jurídico unilateral que determina el abandono irrevocable de un derecho, dentro de los límites establecidos por el ordenamiento. Estos elementos distinguen a la renuncia de otros actos o hechos con los que pudiera a simple vista confundirse: 
el no ejercicio definitivo o el mero retraso en el ejercicio del derecho (en los que no hay declaración de voluntad), la disposición (que es el género del cual la renuncia es una especie y que impediría no sólo la extinción sino también la modificación del derecho), la transacción (negocio jurídico bilateral que mediante concesiones recíprocas decide sobre algún asunto dudoso o litigoso, conforme al art. 1302 Cód. Civ.), etc. (De la Villa, Prados de Reyes).

36. El negocio jurídico que nos ocupa queda invalidado justamente por el principio de la irrenunciabilidad de los derechos del trabajador (art. 57 Const. y varias otras disposiciones). Esta es la regla en el Derecho del Trabajo, mientras que en el Derecho Civil es más bien la excepciọ́n (son irrenunciables en esta última disciplina, por ejemplo, los derechos inherentes a la persona (art. 5 Cód. Civ.). La nulidad de una cláusula no acarrea la de las demás que forman un mismo negocio jurídico: a) ni en el convenio colectivo (art. 48 D.S. 6-71-TR); b) ni en el contrato de trabajo (art. 224 Cód. Civil, aplicado supletoriamente).

37. Respecto de la actuación de este principio cabe plantearse cuatro preguntas fundamentales: ¿desde qué momento un derecho es irrenunciable? ¿sólo los derechos del trabajador son irrenunciables o también algunos del empleador? ¿todos los derechos del trabajador son irrenunciables? ¿es iguál una renuncia ejecutada por un sujeto individual que por un sujeto colectivo? Vamos a analizar las dos primeras interrogantes en este punto y las otras en los siguientes. La doctrina concuerda en que un derecho es irrenunciable tanto antes como después de adquirido, porque lo que no pueden las partes es apartar de la relación constituida entre ellas la vigencia de una norma imperativa. El tema de si ciertos derechos del empleador, señaladamente su poder de dirección, entran también en el campo de la irrenunciabilidad, es más bien controvertido. Es claro, en todo caso, que estaríamos ante una excepción, cuya base normativa no sería el art. 57 Const. sino tal vez el art. V T.P. Cód. Civ. Algunos autores, como Montoya Melgar y Ojeda Avilés (citados por Sala Franco) responderían afirmativamente, en tanto que otros lo harían negativamente (Sala Franco). Este último considera que, a falta de una prohibición expresa por el orde- 
namiento, una interpretación teleológica llevaría a admitir la disposición por el empleador de su poder de dirección. El límite de esta propuesta, con la que coincidimos, sería la desnaturalización de los papeles que corresponden a cada una de las partes de la relación laboral.

38. Con referencia a si todos los derechos del trabajador son o no irrenunciables, De la Villa distingue entre las normas de: a) derecho necesario absoluto, que producen derechos indisponibles en cualquier dirección (a las que deberíamos añadir -siguiendo a García-Perrote Escartín- las máximas de derecho necesario, que producen derechos disponibles hacia abajo); b) derecho necesario relativo, que producen derechos indisponibles hacia abajo pero disponibles hacia arriba; y c) derecho dispositivo, que producen derechos disponibles en cualquier dirección. Serán, en consecuencia, derechos irrenunciables los nacidos de normas de derecho necesario absoluto o relativo por encima de los mínimos (éste es el caso de la costumbre, excepto la llamada por una norma, y el contrato de trabajo). En nuestro ordenamiento, creemos que la fórmula utilizada por el art. 57 Const. permitiría una interpretación extensiva, comprendiendo en la protección a los derechos creados por cualquier fuente normativa o no normativa.

39. La cuestión de los diferentes efectos de la renuncia en las relaciones individuales o colectivas, es también polémica. Mientras hay acuerdo en la doctrina respecto de que la renuncia operada por un sujeto individual será nula (si aquella recayera sobre un derecho nacido de un convenio colectivo o resolución estatal sustitutoria, la base normativa sería el art. 43 D.S. 6-71-TR), no lo hay respecto de la renuncia operada por un sujeto colectivo, dada la supuesta equiparación entre las partes. En esta hipótesis, De la Villa distingue la renuncia hecha por la categoría profesional (a través de un convenio colectivo) respecto de derechos: a) individuales, caso en el cual podría optarse por a.1) el respeto a los derechos adquiridos o por a.2) el predominio del interés colectivo sobre el individual; y b) colectivos, que sería inadmisible si se tratara de derechos básicos. Ya hemos expresado, para el supuesto de la sucesión peyorativa de convenios colectivos, nuestra preferencia por el respeto a los derechos adquiridos (punto 31 de este 
trabajo), lo que se refuerza con la constatación de la insuficiente capacidad de autotutela que en nuestro país poseen las organizaciones sindicales, por causas fácticas y jurídicas. Téngase en cuenta que, una vez celebrado un convenio colectivo -recogiéndose la teoría de la incorporación al nexo contractual-, el sindicato ya no seria titular de las cláusulas normativas, que pertenecerían a cada trabajador individual, sino sólo de las obligacionales, que serían en todo caso las únicas disponibles para él. En consecuencia, a nuestro parecer, el segundo convenio colectivo peyorativo podrá derogar al primero, pero sus efectos sólo comprenderán a los nuevos trabajadores incorporados a la unidad de negociación. No queremos dejar de reconocer, sin embargo, que incluso una concepción de la irreversibilidad de los convenios colectivos, no carecer ia de cierto fundamento.

\section{F. DISCRIMINACION EN PERJUICIO DEL TRABAJADOR}

40. En materia del principio de la igualdad, Rodríguez Piñero distingue entre: a) la igualdad ante la ley (de derecho público), que significa la paridad en la eficacia de las normas, obliga a la actuación imparcial del Estado, aunque permite diferenciar entre situaciones distintas en la búsqueda de la igualdad sustancial; y b) la igualdad de trato (de derecho privado), que significa la consideración igual de los iguales en iguales circunstancias, actuando como limite a los poderes del empleador en sus medidas colectivamente relevantes y a la autonomía colectiva e imponiendo la comparación entre trabajadores de la misma empresa (Blanco, Cremades). En nuestra área jurídica, la igualdad ante la ley es previa a la constitución de la relación laboral y se satisface con el cumplimiento de los derechos mínimos del trabajador, mientras que la igualdad de trato actúa con posterioridad a dicha constitución (Cremades). Esta última es un principio específico del Derecho del Trabajo.

41. Una y otra manifestación del principio de la igualdad prohiben la discriminación, entendida como diferenciación arbitraria, carente de justificación objetiva y razonable, ya sea favorable o adversa a toda persona o al trabajador, respectivamente. Ambas se encuentran recogidas por nuestro ordenamiento y los instrumen- 
tos internacionales sobre derechos humanos aprobados y ratificados por nuestro país: a) la igualdad ante la ley impide la expedición de leyes especiales por la diferencia de las personas (art. 187 Const.) y la discriminación entre éstas por razón de sexo, raza, religión, opinión o idioma (art. 2 inc. 2 Const.), listado complementario al de los instrumentos internacionales que veremos en seguida (art. 7 Declaración Universal de Derechos Humanos, art. 26 Pacto Internacional de Derechos Civiles y Políticos y art. 24 Convención Americana sobre Derechos Humanos); y b) la igualdad de trato invalida las decisiones emanadas de la autonomía privada individual o colectiva que resulten discriminatorias por cualquier causa (art. 42 Const.), con especial referencia a la raza, color, sexo, idioma, religión, opinión política o de cualquier otra índole, origen nacional o social, posición económica, nacimiento o cualquier otra condición (art. 2 inc. 1 Declaración Universal de Derechos Humanos, arts. 2 inc. 1 y 3 Pacto Internacional de Derechos Civiles y Políticos, arts. 2 inc. 2,3 y 7 inc. c Pacto Internacional de Derechos Económicos, Sociales y Culturales, art. 1 Convención Americana sobre Derechos Humanos, y Convenio 111 OIT). Hay particular énfasis en lo específicamente salarial: art. 43 Const., art. 23 inc. 2 Declaración Universal de Derechos Humanos, art. 7 inc. a Pacto Internacional de Derechos Económicos, Sociales y Culturales, y Convenio 100 OIT. La fórmula. pues, es amplia y abierta por la cláusula sobre "cualquier otra condición", que podría comprender la edad, origen étnico, condición civil, orientación sexual, deficiencias físicas, etc. (O'Donnell). A las causas vedadas para una discriminación, habría que agregarles el ejercicio de cualquier derecho, señaladamente los derivados de la libertad sindical (Convenio 98 OIT).

42. ¿Cómo opera el principio de la igualdad de trato? La secuencia de aplicación del principio será la siguiente: a) el empleador toma una decisión unilateral o la adopta por acuerdo con la organización sindical, consistente en el establecimiento de una regla general para la empresa; b) sin causa justificada se excluye -o eventualmente se incluye- en ella a un trabajador; c) éste impugna la medida ante la autoridad competente, que en nuestro caso es la Autoridad Administrativa de Trabajo o el Fuero de Trabajo, según el vínculo laboral esté vigente o no, respectivamente 
(aunque creemos que deberia ser el Fuero de Trabajo, por carecer la primera de jurisdicción ): d) la carga de la prueba recae en el trabajador (Sagardoy Bengoechea), aunque en algunos ordenamientos, en materia de libertad sindical, la carga se invierte (Villavicencio Ríos); y e) la autoridad competente ordena el cese de la medida discriminatoria.

43. Por último, debemos añadir -siguiendo a Rodríguez Piñero- que este tema debe ser leído a la luz de la búsqueda de la igualdad sustancial. configurada como un valor superior del ordenamiento, insatisfecho con la mera protección al trabajador, que pretende corregir la realidad misma de la cual deriva la necesidad de esa protección. En nuestra Constitución se encuentra consagrada en artículos como el 42 y el 80 , sobre todo, en virtud de los cuales todos.los habitantes de la República deben tener por igual la oportunidad de una ocupación útil, en el marco de un Estado promotor de la justicia y los derechos humanos. 


\section{G. BIBLIOGRAFIA}

- BLANCO, Juan Eugenio

La consideración igual de los iguales, en: Revista de Politica Social, Madrid, Instituto de Estudios Políticos, 1967, No. 74.

- CAMPS RUIZ, Luis Miguel

Los conflictos entre normas laborales, en: AA.VV., Fucntes de la relación laboral y criterios de aplicación en el Estatuto de los Trabajadores, Madrid, Instituto de Estudios Sociales, 1981.

- CREMADES, Bernardo María

El tratamiento igual en la empresa, en: Revista de Politica Social, Madrid, Instituto de Estudios Políticos, 1969, No. 83.

- DE LA CUEVA, Mario

El nuevo Derecho mexicano del Trabajo, México, Editorial Porúa S.A., 1981.

- DE LA VILLA GIL, Luis Enrique

El principio de la irrenunciabilidad de los derechos laborales. en: Revista de Política Social, Madrid, Instituto de Estudios Políticos, 1970, No. 85.

- ERMIDA URIARTE, Oscar

Empresas multinacionales $y$ Derecho Laboral, Montevideo. Ediciones Jurídicas Amalio M. Fernández, 1981.

- GARCIA-PERROTE ESCARTIN, Ignacio

Ley y autonomia colectiva. Un estudio sobre las relaciones entre la norma estatal y el convenio colectivo, Madrid, Ministerio de Trabajo y Seguridad Social, 1987.

- MARTIN VALVERDE, Antonio

Concurrencia y articulación de normas laborales, en: Revista de Política Social, Madrid, Instituto de Estudios Políticos, 1978. No. 119. 
- MUÑOZ CONDE, Francisco

Introducción al Derecho Penal, Barcelona, Bosch, Casa Editorial S.A., 1975.

- NEVES MUJICA, Javier

Fuentes y principios laborales en la Constitución, en: Trabajo y Constitución, Lima, Cultural Cuzco S.A., Editores, 1989. Determinación de la norma más favorable, ponencia presentada al X Congreso Iberoamericano de Derecho del Trabajo y de la Seguridad Social, Montevideo, abril de 1989.

- O'DONNELL, Daniel

Protección internacional de los derechos humanos, Lima, Comisión Andina de Juristas, 1988.

- OJEDA AVILES, Antonio

El principio de condición más beneficiosa, en: Revista de Politica Social, Madrid, Instituto de Estudios Políticos. 1982, No. 134.

- PLA RODRIGUEZ, Américo

Los principios del Derecho del Trabajo, Buenos Aires, Ediciones Depalma, 1978.

- PRADOS DE REYES, Francisco Javier

Renuncia y transacción de derechos en el Estatuto de los Trabajadores, en: Revista de Politica Social, Madrid, Instituto de Estudios Políticos, 1980, No. 127.

- RODRIGUEZ PIÑERO, Miguel

El principio de igualdad y las relaciones laborales, en: Revista de Politica Social, Madrid, Instituto de Estudios Políticos, 1979, No. 121.

- RUBIO CORREA, Marcial

El sistema juridico, Introducción al derecho, Lima, Pontificia Universidad Católica del Perú, Fondo Editorial, 1984.

Titulo Preliminar. Para leer el Código Civil III, Lima, Pontificia Universidad Católica del Perú, Fondo Editorial, 1986. 
- SAGARDOY BENGOECHEA, Juan Antonio

Los principios de aplicación del Derecho del Trabajo, Madrid, ACARL, 1989.

- SALA FRANCO, Tomás

El principio de la condición más beneficiosa, en:Revista de Politica Social, Madrid, Instituto de Estudios Políticos, 1977, No. 114.

Lecciones de Derecho del Trabajo, (Sala Franco, Director), Valencia, Tirant Lo Blanch, 1988.

- TOVAR GIL, María del Carmen y Javier

Derecho Internacional Privado, Lima, Fundación M.J. Bustamante De la Fuente, 1987.

- VILLAVICENCIO RIOS, Alfredo

Constitución y libertad sindical, en: Trabajo y Constitución, Lima, Cultural Cuzco S.A. Editores, 1989. 